\title{
Thyroid dysfunction in pregnancy: practical perspective
}

\begin{abstract}
Pregnancy is a complex endocrine and metabolic status in life of women, therefore role of the thyroid physiology during this period will be profoundly affected, this has been attributed to the complex interplay of Human chorionic gonadotrophin that acts as TSH receptors' stimulant, more estrogen is produced by placenta will lead to rise in the serum level of Thyrogublin binding protein, change in iodine homeostasis, and hemodynamic changes. From $12^{\text {th }}-16^{\text {th }}$ week of pregnancy, the fetus is entirely dependent on the thyroid status of the mother, therefore any disruption in this metabolic milieu will lead to negative outcomes on both the fetus and the mother. Therefore, the current guidelines have stressed on appropriate management of thyroid dysfunction in pregnancy with particular interest on early pregnancy, a critical period for neurocognitive development, then throughout the pregnancy and postpartum period (Figure 1).
\end{abstract}

Volume 12 Issue 5 - 2021

\section{Saadi JS AlJadir}

Ministry of Higher Education \& Scientific Research, Iraq

Correspondence: Saadi JS AlJadir PhD, MRCP (UK), FRCP (L), FRCP $(G)$, FACE (US, Ministry of Higher Education \& Scientific Research, PO Box 498, Nassiryia, Thi Qar, Iraq,

Tel +9647813902926, Email saljadir5 I@gmail.com

Received: October 05, 202 I | Published: October 22, 202 I

Keywords: graves' disease, thyroid stimulating hormone, postpartum thyroiditis

Abbreviations: TSH, thyroid stimulating hormone; FT4, free thyroxine; FT3, free triiodothyronine thyroxine binding globulin; TSI, thyrotropin stimulating immunoglobulin; TRABs, thyrotropin receptor antibodies; MMI, methimazole; PTU, propylthiouracil; RIU, radio-iodine uptake; RIA, radio-iodine ablation; RT3, reverse triiodothyronine; L-Thyroxine, levothyroxine; TPO, thioperoxidase; TG, thyroglobulin; HCG, human chorionic gonadotrophin

\section{Introduction}

Thyroid disease is a common endocrine disorder and second to diabetes mellitus affecting women of child-bearing age, the current guidelines recommend optimal management during pregnancy, it has been agreed that maternal thyroid dysfunction might result in increased risk of miscarriage, placental abruption, hypertension, preterm delivery physical and neurocognitive growth restriction. Routine screening for thyroid function is not recommended so far by most of the available data, but recommend targeted screening of women at high risk of thyroid dysfunction:

1) Thyroid disease, goiter, thyroid nodule, iodine deficient regions

2) T1 diabetes mellitus

3) Autoimmune disease; Celiac disease

4) Current or past use of thyroid therapy.

5) Family history of autoimmune thyroid disease.

6) History of neck irradiation, thyroid surgery.

7) Treated for Hyperthyroidism, Radioiodine, or surgery
8) Bad obstetric history; recurrent abortions

9) Morbid obesity.

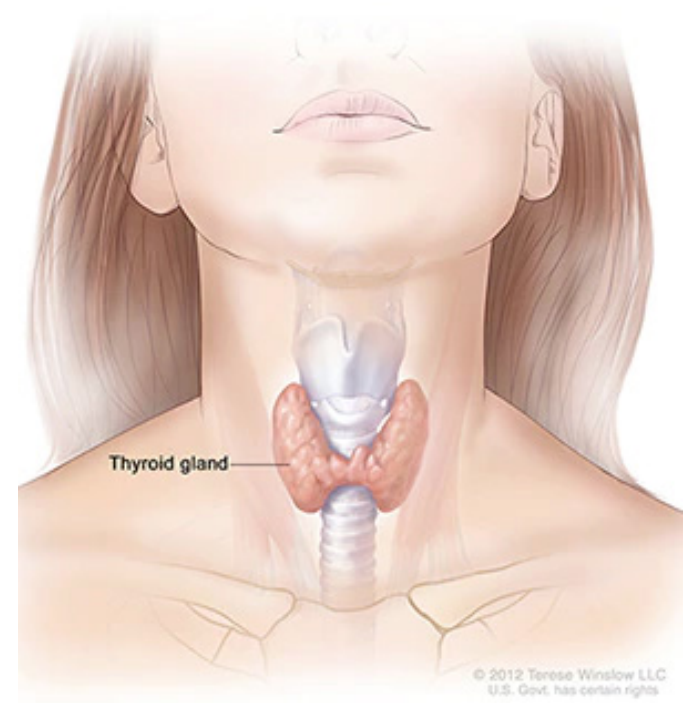

Figure I From NIDDK (Thyroid \& pregnancy).

Appropriate management results in improved outcomes, demonstrating the importance of proper diagnosis and treatment. In women with hypothyroidism, levothyroxine is titrated to achieve a goal serum TSH level for pregnancy reference (Table 1). The preferred treatment for hyperthyroidism is antithyroid medications in lowest dose required to attain a serum FT4 level in the upper range of normal.

Table I Trimester-specific reference ranges for thyroid function tests

\begin{tabular}{lllll}
\hline Test & Non-pregnant & Ist trimester & 2nd trimester & 3rd trimester \\
\hline TSH mlU/L & $0.3-4.3$ & $0.1-2.5$ & $0.2-3.0$ & $0.3-3.0$ \\
TBG g/dl & $1.3-3.0$ & $1.8-3.2$ & $2.8-4.0$ & $2.6-4.2$ \\
Free T4 ng/dl & $0.8-1.7$ & $0.8-1.2$ & $0.6-1.0$ & $0.5-08$ \\
\hline
\end{tabular}


Table Continued.

\begin{tabular}{lllll}
\hline Test & Non-pregnant & Ist trimester & 2nd trimester & 3rd trimester \\
\hline TotalT4 mcg/dl & $5.4-11.7$ & $6.5-10.1$ & $7.5-10.3$ & $6.3-9.7$ \\
Free T3 pg/ml & $2.4-4.2$ & $4.1-4.4$ & $4.0-4.2$ & Not reported \\
Total T3 ng/dl & $77-135$ & $97-149$ & $117-169$ & $123-162$ \\
\hline
\end{tabular}

Source:American Thyroid Association, (Obstet Gynecol 2010) Pregnancy and Lab, tests

Postpartum thyroiditis is the most common form of postpartum thyroid dysfunction which is a form of transient immunologic disorder of the thyroid and may present as hyper- or hypothyroidism. Treatment is directed towards the symptoms more than biochemical results therefore specific treatment is not required in majority of cases, in hyperthyroid state; symptomatic treatment is given. While thyroxine is given for hypothyroid women who are symptomatic, breastfeeding, or planned for pregnancy (Figure 2).

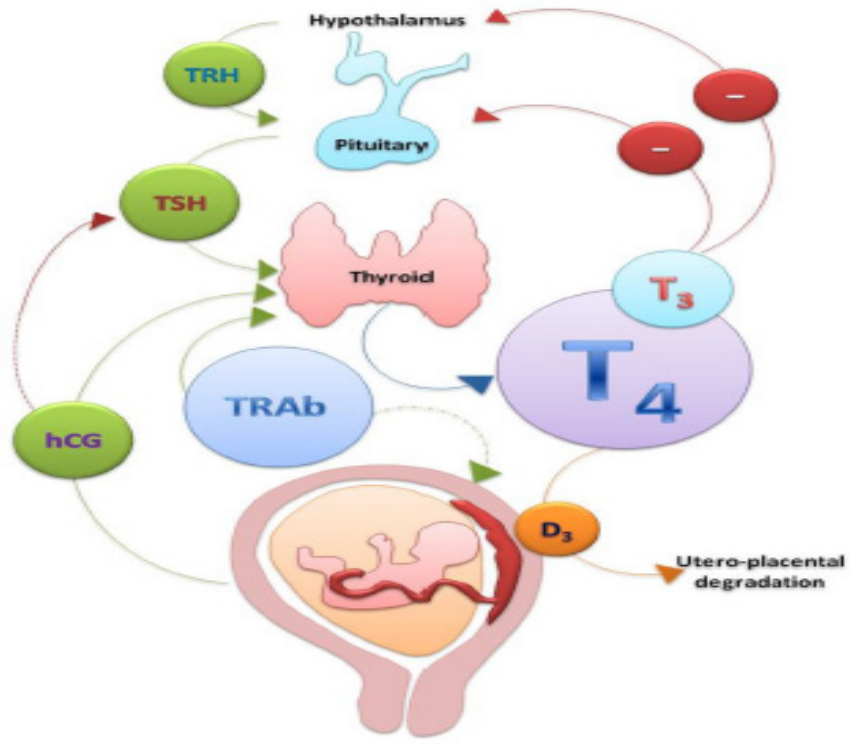

Figure 2 Hypothalamic-pituitary-thyroid axis and pregnancy.

Source: E. Tingi et al. / Journal of Clinical \& Translational Endocrinology 6 (2016) 37-49.

\section{Pregnancy and thyroid gland}

Pregnancy is a complex endocrine condition and has modified immunologic response, pregnancy exerts stress effect on the thyroid as there is needful rise for metabolic rate in response to changes in body weight, composition, plasma volume and cardiac output which are critical for fetal growth throughout the pregnancy. It carries multivariate effects on thyroid gland and hormone homeostasis. The gland might increase in volume by $10-15 \%$ (might be undatable clinically, but could be by highly sensitive ultrasound), some women might be goitrous especially in iodine-deficient regions, and near $50 \%$ increase in hormones production.

Metabolic demands are profoundly increased during pregnancy and therefore thyroid hormone requirement needs to be adjusted and optimized. Inadequate thyroxine replacement can have negative impacts on the growing fetus, including increased risk of preterm birth, low birthweight, and miscarriage.

These normal physiological changes are critical for nurturing the fetus and maintaining the pregnancy, on other hand the changes in thyroid hormones and the changes in the pituitary -thyroid axis make it difficult for the caring clinician to distinguish between normal and abnormal hormonal values.

These affects are seen especially in the first trimester, as the fetus depends entirely on his mother's transplacental free T3 and T4 until it develops its own thyroid gland at $11-12^{\text {th }}$ week of gestation. The fetus's thyroid secretes adequate thyroid hormones until $16^{\text {th }}$ week of gestation. However the cord blood even at late pregnancy has still one third of mother T4, so efficient thyroid status of the mother is essential for fetal development throughout the pregnancy, but certainly in different proportions.

Thyroid physiology undergoes many changes during pregnancy. In the first trimester, beta hCG rises. TSH and hCG share similar beta subunits, allowing the hCG to directly stimulate thyroid tissue, this leads to increased FT3 and FT4 and, therefore, TSH suppression may occur in the first trimester. As beta hCG falls in the second and third trimester, TSH normalizes. there are other associated metabolic changes that have been recognized with pregnancy:

a. Increased iodine clearance

b. Increased uptake of T3 and T4

c. Increased estrogen, causing increased thyroxine-binding globulin (TBG), therefore total T4 is increased in 50\%.

d. T4 undergoes transplacental passage to supply the fetus

e. Increased renal excretion of T4

f. Breakdown of T4 by placental deiodinases.

Increased estrogen levels result in a $50 \%$ elevation of thyroxine binding globulin with a concomitant $50 \%$ increase in total thyroxine (TT4) and triiodothyronine, eventually there might be slight increase in free hormones, but it is of little clinical significance. Placental production of human chorionic gonadotropin (hCG), which acts as a weak TSH, drives a decrease TSH upper limit of normal due to cross reactivity of hCG at the TSH receptor. These critical adaptations in pregnancy are necessary for a healthy pregnancy and a healthy baby especially in early pregnancy and fetal development.

However, the normal physiological changes in thyroid hormone levels make it difficult to distinguish between normal and abnormal hormonal values. In last 2 decades the ability to handle thyroid disorders and efficiently diagnose these abnormalities has been increasingly entertained and the attention directed toward the researches which have linked the hormonal disturbances to the increase incidence of miscarriage, premature delivery, gestational hypertension and diabetes, preeclampsia and decreased IQ in the newborns.

In view of these physiological changes, pregnancy based standard values of TSH hormone values should be considered and special thyroid function interpretations by hormonal expert should be undertaken as well (Table 1). 


\section{Practical points in the management of thyroid disorders in pregnancy}

\section{Hypothyroid disease}

The condition can be divided into:

1. Overt hypothyroidism affecting $0.5-1 \%$ cent of all pregnancies, the most common are Hashimoto's thyroiditis, iodine deficiency, surgery and Radioiodine ablation. Overt hypothyroidism is defined as thyroid hormone deficiency with low FT4 and elevated TSH levels.

2. Subclinical hypothyroidism $2-3 \%$, of the pregnancies, in some series the patients' numbers might be widely varied (up to $15 \%$ had been reported) according to the values of TSH upper threshold that had been considered, subclinical hypothyroidism refers to asymptomatic individuals with elevated TSH (above upper limit of pregnancy ranges) and normal FT4.

The most common cause of hypothyroidism in iodine replete regions is iodine deficiency while the autoimmune disorder known as Hashimoto's thyroiditis in iodine -sufficient countries.

Symptoms of hypothyroidism, cold intolerance, tiredness, and weight gain may be confused with normal pregnancy. Therefore, might be overlooked.

Other symptoms may include:

i. Constipation

ii. Concentration difficulty or memory problems

iii. Muscle cramps

iv. Hair Fall

v. Weight gain.

\section{Hyperthyroid diseases}

It is less common than hypothyroidism with an incidence during pregnancy of $0.2 \%$.The most common cause is the autoimmune disorder; Grave's disease , about $95 \%$ of overt cases .In this disorder, TSH receptors Abs (TRABs), they are thyroid-stimulating immunoglobulin (TSI), that cause the thyroid to be overactive, increase in size and produces more thyroid hormones T4 and T3 in different proportions.

Removal of the gland by surgery or radioactive iodine ablation, body can still have circulating Anti-bodies. If their titers are too high, TSI will cross the placenta and reach the fetus thyroid, stimulate fetal gland, and result into neonatal goiter and hyperthyroidism.

Symptoms of hyperthyroidism may mimic those of normal pregnancy, such as an increased heart rate, sensitivity to hot intolerance, and fatigue.

Other symptoms might be:

a. Palpitation and occasionally irregular heartbeat

b. Anxiety and nervousness

c. Severe nausea or vomiting or intense morning sickness

d. Tremor

e. Insomnia

f. Weight loss or low weight gain (as happens usually in pregnancy) despite good appetite

g. Frequent bowel motions

h. Eye signs in extreme cases (Table 2).

\section{Diagnosis of thyroid disease in pregnancy}

Hyperthyroidism and hypothyroidism in pregnancy are diagnosed based on symptoms, physical exam, and biochemical tests to measure levels of sensitive thyroid-stimulating hormone (sTSH) with special pregnancy reference more narrow range than in non-pregnant range, Free T4, and for hyperthyroidism also FreeT3, specific Antibodies like Anti-TPO, Anti-thyroglobulin, or TRABS.

The preferred method for TSH, Free T4, T3 and Abs is Quantitative Chemiluminescent immunoassay, in selected cases free hormone might require special procedure; Quantitative Equilibrium Dialysis and High-Performance Liquid Chromatography, in selected cases Free hormones might require special procedures, Quantitative Equilibrium Dialysis and High-Performance Liquid Chromatography.

Table 2 Effects associated with thyroid disease and pregnancy

\begin{tabular}{|c|c|c|c|c|}
\hline Condition & Preconception & Pregnancy & Post-partum & Medications \\
\hline $\begin{array}{l}\text { Hyperthyroidism } \\
\text { Overt }\end{array}$ & $\begin{array}{l}\text { Congenital } \\
\text { Malformations }\end{array}$ & $\begin{array}{l}\text { Maternal: Heart failure, Placental } \\
\text { Abruption, Preeclampsia, preterm } \\
\text { delivery, Fetal : goiter, intrauterine } \\
\text { growth restriction, small for } \\
\text { gestational age, still birth , thyroid } \\
\text { dysfunction }\end{array}$ & - & $\begin{array}{l}\text { Methimazole:Aplasia Cutis, Choanal } \\
\text { or esophageal atresia .skin reactions, } \\
\text { agranulocytosis } \\
\text { Propylthiouracil: maternal liver toxicity } \\
\text { \& failure, } \\
\text { polyarthritis, anemia, vasculitis }\end{array}$ \\
\hline $\begin{array}{l}\text { Hyperthyroidism } \\
\text { Subclinical }\end{array}$ & - & none & - & Not recommended \\
\hline $\begin{array}{l}\text { Hypothyroidism } \\
\text { Overt }\end{array}$ & $\begin{array}{l}\text { Decrease fertility, } \\
\text { increase miscarriage }\end{array}$ & $\begin{array}{l}\text { Anemia, Fetal neurocognitive defect, } \\
\text { gestational hypertension, low } \\
\text { birth weight, miscarriage, placental } \\
\text { abruption, preeclampsia, preterm } \\
\text { birth }\end{array}$ & $\begin{array}{l}\text { Maternal thyroid } \\
\text { dysfunction, } \\
\text { hemorrhage }\end{array}$ & $\begin{array}{l}\text { Levothyroxine: little to no effect on } \\
\text { hypertensive disorders and abruption; } \\
\text { reduced miscarriage and preterm } \\
\text { birth, and improves fetal intellectual } \\
\text { development }\end{array}$ \\
\hline
\end{tabular}


Table Continued...

\begin{tabular}{|c|c|c|c|}
\hline Condition & Preconception & Post-partum & Medications \\
\hline $\begin{array}{l}\text { Hypothyroidism } \\
\text { Subclinical }\end{array}$ & $\begin{array}{l}\text { Effects similar to } \\
\text { over hypothyroidism } \\
\text { but less } \\
\text { documentation exist }\end{array}$ & & \\
\hline
\end{tabular}

Source: Cochrane Data base (Interventions for Clinical \& subclinical Hypothyroidism in pregnancy 20I0,J Clin Endocrinol Meta 20I2

ATA Task force guidelines 20II

\section{Treatment of thyroid disease in pregnancy}

For women who require treatment for hyperthyroidism, an antithyroid medications (thioamides) that blocks production of thyroid hormones is used. Two compounds are used currently; Propylthiouracil (PTU and Methimazole both compounds are given cautiously especially in early pregnancy due to reported cases of embryopathies, we have carried the schedule of giving PTU in first three months of pregnancy then we switch to Methimazole to avoid hepatic toxicity.

Although we need to give it in $100-400 \mathrm{mg} /$ day in divided doses, while Methimazole can be given in dose of 10-30 in one or two dose afterwards.

Adverse effects are mostly related to leukocytes drop that rarely mandates medication withdrawal, other common skins lesions, majority are transient and non-serious. Carbimazol on the other hand is used in some countries, it is the active metabolite of Methimazole and has almost same efficacy.

In rare cases that don't respond to anti-thyroid medications, or we cannot utilize high doses ( $>30 \mathrm{mg}$ Methimazole, $>400 \mathrm{mg}$ PTU) or serious adverse effects developed, surgery with partial removal of the gland is the preferred option during $2^{\text {nd }}$ trimester can be undertaken, radio-iodine ablation is contraindicated in pregnancy.

Hypothyroidism is treated levothyroxine, and dose is titrated according to TSH level and monitors the optimization of euthyroid state as early as 4 weeks.

If you have hypothyroidism and are taking levothyroxine, it is important to notify your doctor as soon as you know you are pregnant, so that the dose of levothyroxine can be increased accordingly to accommodate the increase in thyroid hormone replacement, for practical reason we advise the patient as soon as she receives the positive test of pregnancy or missed period the next step will be:

i. Extra 2 doses of her daily thyroxine

ii. or increase $20-30 \%$ of her total weekly intake

iii. In planned pregnancy the patient it is advisable to have TSH less than 2.5 (some are more drastic of less than $1.5 \mathrm{mIU} / \mathrm{L}$ ).

Until the biochemical testing will be undertaken, and thyroxine dose adjusted, early TSH value is less than 2.5 in first trimester and less than 3 throughout $2^{\text {nd }}$ and $3^{\text {rd }}$ trimesters. The hormones should be taken on empty stomach preferably 1 hour before breakfast, medications that might be taken during pregnancy may interfere with thyroxine absorption and this will create hormonal perturbation and eventually unwanted outcome on the fetus, calcium, iron, Antacids should be given 3-4 hours of taking thyroxine.
For patients who discover during $1^{\text {st }}$ trimester, the dose of thyroxine depends on severity of the condition (TSH level) and size of the patient and other associated medical conditions (Table 3).

Table 3 Adjustment of levothyroxine dose to TSH level

\begin{tabular}{ll}
\hline TSH mIU/L & L-thyroxine Dose /day \\
\hline 5 to $<10$ & $25-50$ \\
$10-20$ & $50-75$ \\
$>20$ & $75-100$ \\
\hline
\end{tabular}

Source: Best Pract Res Clin Endocrinol Metab. 2004; I 8(2):2 I 3-224

Recent studies support thyroxine replacement in women with subclinical hypothyroidism undergoing assisted reproduction technologies, to improve pregnancy outcome. Women with subclinical hypothyroidism should be tested for antithyroid antibodies (AntiTPO) as this may have negative impact in pregnancy moreover may also be associated with other auto-immune diseases.

At present there are no data to support treating pregnant women who have subclinical hypothyroidism if they do not have antibodies. Thyroxine therapy for such case hasn't proven any benefit.

\section{Postpartum thyroiditis}

The most common cause of postpartum thyroid dysfunction is postpartum thyroiditis, which affects $1.1 \%$ to $21.1 \%$ of women. In order not to be missed the diagnosis this condition should be considered in the differential diagnosis of postpartum depression especially in women with previous antibodies testing.

The clinical presentation varies between hyperthyroidism (in the absence of toxic adenoma or TRABs) and hypothyroidism, it is usually a transient autoimmune phenomenon occurring within 12 month after delivery, some women might continue of being hypothyroid, therefore should be monitored annually.

Majority of women recovered spontaneously, hyperthyroid state can be managed by symptomatic treatment like $\beta$-Blockers and reassurance, few from hypothyroid women who symptomatic or breast feeding might benefit from thyroxine therapy.

\section{Thyroid nodule}

When a thyroid nodule is found on clinical examination or by pregnant lady, it can be investigated safely with ultrasound, the size and consistency of the nodule can be assessed by high resolution ultrasound, small solid nodules could be investigated after delivery, Fine needle aspirates for bigger and suspicious lesions preferably by ultrasound -guided fine -needle aspiration and cytology. Occasionally small lesion intervention is carried out in those have high risk of thyroid neoplasm or ultrasonic suspicious for malignancy (Table 4). 
Table 4 Treatment of Thyroid disease in pregnancy

\begin{tabular}{|c|c|c|c|c|}
\hline Condition & Treatment & Treatment goal & Monitoring & Antepartum testing \\
\hline Hyperthyroidism & $\begin{array}{l}\text { Methimazole (preferred } \\
\text { agent } \\
\text { Ist trimester) } 10-30 \mathrm{mg} / \text { day } \\
\text { in Ix or } 2 x \text { dosing } \\
\text { Propylthiouracil: } \\
100-450 \mathrm{mg} / \text { day in } 3 x\end{array}$ & $\begin{array}{l}\text { Serum Free T4 in upper one- } \\
\text { third of normal range }\end{array}$ & $\begin{array}{l}\text { Estimation of serum } \\
\text { TSH \& Free T4,T3 } \\
\text { every } 2 \text { weeks until } \\
\text { stable medication } \\
\text { dosage }\end{array}$ & $\begin{array}{l}\text { Weekly starting at } 32 \text { nd } \\
-34 \text { th in women with } \\
\text { poorly controlled } \\
\text { Consider testing earlier or } \\
\text { more frequent in patients } \\
\text { with other indications for } \\
\text { testing }\end{array}$ \\
\hline Hypothyroidism & $\begin{array}{l}\text { Levothyroxine } 100-150 \mathrm{mcg} \\
\text { /day }\end{array}$ & Serum TSH $<2.5 \mathrm{mIU} / \mathrm{L}$ & $\begin{array}{l}\text { Estimation of serum } \\
\text { TSH at 4-then } \\
\text { every 4-6 weeks } \\
\text { until 20th week and } \\
\text { on stable dose } \\
\text { Then on 24th } \\
\text {-28th, then on } \\
\text { 32nd -34th week of } \\
\text { gestation }\end{array}$ & $\begin{array}{l}\text { For women with coexisting } \\
\text { conditions or obstetric } \\
\text { indications }\end{array}$ \\
\hline
\end{tabular}

Source:ATA 201 I,ACOG,Am J Obs Gynecol 2002, J Clin Endo Metab 2012

\section{Recommended daily intake of iodine}

Iodides are essential substrates for synthesis of thyroid hormones, metabolic changes during pregnancy influence the iodides homeostasis, intake, turnover and excretion, therefore special attention should be considered for optimize the intake to fulfill the requirement of the mother' and the fetus thyroid, as inappropriate handling of this aspect will lead to adverse effect on the prergnancy and fetal outcomes.

Many countries around the world advocate supplementation of table salt with iodides, In the US, water and dairy product are iodinated as well! I.
WHO recommends ingestion of approximately $250 \mathrm{mcg}$ iodine daily for pregnant and lactating women? The United States Institute of Medicine (IOM) recommended daily allowance for iodine is $220 \mathrm{mcg}$ during pregnancy and $290 \mathrm{mcg}$ during lactation.

The American Thyroid Association strongly advocates adequate daily iodine intake in pregnancy, specifically recommending that women in North America take $150 \mathrm{mcg}$ of iodine daily as a potassium iodide supplement.

No supplemental iodine is required in those taking adequate thyroxine therapy and Anti-thyroid medications in hyperthyroidism during pregnancy (Table 5).

Table 5 World Health Organization and Institute of medicine recommendations for dietary iodine intake

\begin{tabular}{lll}
\hline & $\begin{array}{l}\text { WHO recommended } \\
\text { daily iodine intake }\end{array}$ & $\begin{array}{l}\text { IOM recommended daily } \\
\text { iodine intake }\end{array}$ \\
\hline Adequate intake for nonpregnant adult & $150 \mathrm{mcg}$ & $150 \mathrm{mcg}$ \\
Adequate intake in pregnant women & $250 \mathrm{mcg}$ & $220 \mathrm{mcg}$ \\
Adequate intake for Lactating women & $250 \mathrm{mcg}$ & $290 \mathrm{mcg}$ \\
\hline
\end{tabular}

Source:WHO 2007, J Clin Endo Metab Vol. 942009

\section{Breastfeeding and use of anti-thyroid medications}

Before and for decades, we had advised against breastfeeding in women treated with anti-thyroid medications, however recent studies have shown that only minute quantities of PTU and MMI are secreted in milk, Hence, women with hyperthyroidism using low-to-moderate doses of MMI $(<20 \mathrm{mg})$ or PTU $(<300 \mathrm{mg})$ can nurse their children. American thyroid Association prefers MMI in this setting. ${ }^{1-32}$

\section{Acknowledgments}

None.

\section{Funding}

None.

\section{Conflicts of interest}

The authors did not report any potential conflicts of interest.

\section{References}

1. Stagnaro-Green A, Abalovich M, Alexander E, et al. American thyroid association taskforce on thyroid disease during pregnancy and postpartum 2011 Guidelines of the American Thyroid Association for the diagnosis and management of thyroid disease during pregnancy and postpartum. Thyroid. 21:1081-1125.

2. Abalovich M, Amino N, Barbour LA, et al. Management of thyroid dysfunction during pregnancy and postpartum: an endocrine society clinical practice guideline. J Clin Endocrinol Metab. 2007;92 Suppl:s1-47.

3. Reid SM, Middleton P, Cossich MC, et al. Interventions for clinical and subclinical hypothyroidism in pregnancy. Cochrane Database Syst Rev. 2010;(7):CD007752. 
4. De Groot L, Abalovich M, Alexander EK, et al. Management of thyroid dysfunction during pregnancy and postpartum: an Endocrine Society clinical practice guideline. J Clin Endocrinol Metab. 2012;97(8):25432565 .

5. Stagnaro-Green A, Abalovich M, Alexander E, et al. American thyroid association taskforce on thyroid disease during pregnancy and postpartum. Guidelines of the American Thyroid Association for the diagnosis and management of thyroid disease during pregnancy and postpartum. Thyroid. 2011;21(10):1081-1125.

6. American College of Obstetrics and Gynecology. ACOG practice bulletin no. 37. Thyroid disease in pregnancy. Obstet Gynecol. 2002;100(2):387396.

7. Yassa L, Marqusee E, Fawcett R, et al. Thyroid hormone early adjustment in pregnancy (the THERAPY) trial. J Clin Endocrinol Metab. 2010;95(7):3234-3241

8. Lee RH, Spencer CA, Mestman JH, et al. Free T4 immunoassays are flawed during pregnancy. Am J Obstet Gynecol. 2009;200(3):260.e1-260. e6.

9. Abbassi-Ghanavati M, Greer LG, Cunningham FG. Pregnancy and laboratory studies: a reference table for clinicians. Obstet Gynecol. 2009;114(6):1326-1331.

10. Vaidya B, Anthony S, Bilous M, et al. Detection of thyroid dysfunction in early pregnancy: universal screening or targeted high-risk case finding? $J$ Clin Endocrinol Metab. 2007;92(1):203-207.

11. Negro R, Schwartz A, Gismondi R, et al. Universal screening versus case finding for detection and treatment of thyroid hormonal dysfunction during pregnancy. J Clin Endocrinol Metab. 2010;95(4):1699-1707.

12. Momotani N, Ito $\mathrm{K}$, Hamada $\mathrm{N}$, et al. Maternal hyperthyroidism and congenital malformation in the offspring. Clin Endocrinol (Oxf). 1984;20(6):695-700.

13. Neale DM, Cootauco AC, Burrow G. Thyroid disease in pregnancy. Clin Perinatol. 2007;34(4):543-557.

14. Stagnaro-Green A. Overt hyperthyroidism and hypothyroidism during pregnancy. Clin Obstet Gynecol. 2011;54(3):478-487.

15. Rovet JF. Neurodevelopmental consequences of maternal hypothyroidism during pregnancy. In: Program and abstracts from the 76th annual meeting of the American Thyroid Association; September 30 - October 3, 2004; Vancouver, British Columbia. Thyroid. 2004;14(9):710.

16. Männistö T, Vääräsmäki $M$, Pouta $A$, et al. Thyroid dysfunction and autoantibodies during pregnancy as predictive factors of pregnancy complications and maternal morbidity in later life. $J$ Clin Endocrinol Metab. 2010;95(3):1084-1094.

17. Mamede da Costa S, Sieiro Netto L, Coeli CM, et al. Value of combined clinical information and thyroid peroxidase antibodies in pregnancy for the prediction of postpartum thyroid dysfunction. Am J Reprod Immunol. 2007;58(4):344-349.
18. Di Gianantonio E, Schaefer C, Mastroiacovo PP, et al. Adverse effects of prenatal methimazole exposure. Teratology. 2001;64(5):262-266.

19. Mandel SJ. Hypothyroidism and chronic autoimmune thyroiditis in the pregnant state: maternal aspects. Best Pract Res Clin Endocrinol Metab. 2004;18(2):213-224.

20. Casey BM, Dashe JS, Wells CE, et al. Subclinical hyperthyroidism and pregnancy outcomes. Obstet Gynecol. 2006;107(2 pt 1):337-341.

21. Wing DA, Millar LK, Koonings PP, et al. A comparison of propylthiouracil versus methimazole in the treatment of hyperthyroidism in pregnancy. Am J Obstet Gynecol. 1994;170(1 pt 1):90-95.

22. Mitsuda N, Tamaki H, Amino N, et al. Risk factors for developmental disorders in infants born to women with Graves disease. Obstet Gynecol. 1992;80(3 pt 1):359-364.

23. Luton D, Le Gac I, Vuillard E, et al. Management of Graves' disease during pregnancy: the key role of fetal thyroid gland monitoring. $J$ Clin Endocrinol Metab. 2005;90(11):6093-6098.

24. ACOG practice bulletin. Antepartum fetal surveillance. Number 9, October 1999 (replaces Technical Bulletin Number 188, January 1994). Clinical practice management guidelines for obstetrician-gynecologists. Int $J$ Gynaecol Obstet. 2000;68(2):175-185

25. Muller AF, Drexhage HA, Berghout A. Postpartum thyroiditis and autoimmune thyroiditis in women of childbearing age: recent insights and consequences for antenatal and postnatal care. Endocr Rev 2001;22(5):605-630.

26. Azizi F. The occurrence of permanent thyroid failure in patients with subclinical postpartum thyroiditis. Eur J Endocrinol. 2005;153(3):367-371.

27. Li Y, Shan Z, Teng W, et al. Abnormalities of maternal thyroid function during pregnancy affect neuropsychological development of their children at 25-30 months. Clin Endocrinol (Oxf). 2010;72:825-829.

28. Henrichs J, Bongers-Schokking JJ, Schenk JJ, Ghassabian A, et al. Maternal thyroid function during early pregnancy and cognitive functioning in early childhood: the generation R study. J Clin Endocrinol Metab. 2010;95:4227-4234.

29. Stagnaro-Green A. Approach to the patient with postpartum thyroiditis. $J$ Clin Endocrinol Metab. 2012;97:334-342.

30. Alexander EK, Pearce EN, Brent GA, et al. 2017 guidelines of the American thyroid association for the diagnosis and management of thyroid disease during pregnancy and the postpartum. Thyroid. 2017;27:315-389.

31. Glinoer D. The regulation of thyroid function in pregnancy: pathways of endocrine adaptation physiology to pathology. Endocr Rev. 1997;18:404433.

32. Andersen S, Karmisholt J, Pedersen KM, et al. Reliability of studies of iodine intake and recommendations for number of samples in groups and in individuals. Br J Nutr. 2008;99:813-818. 